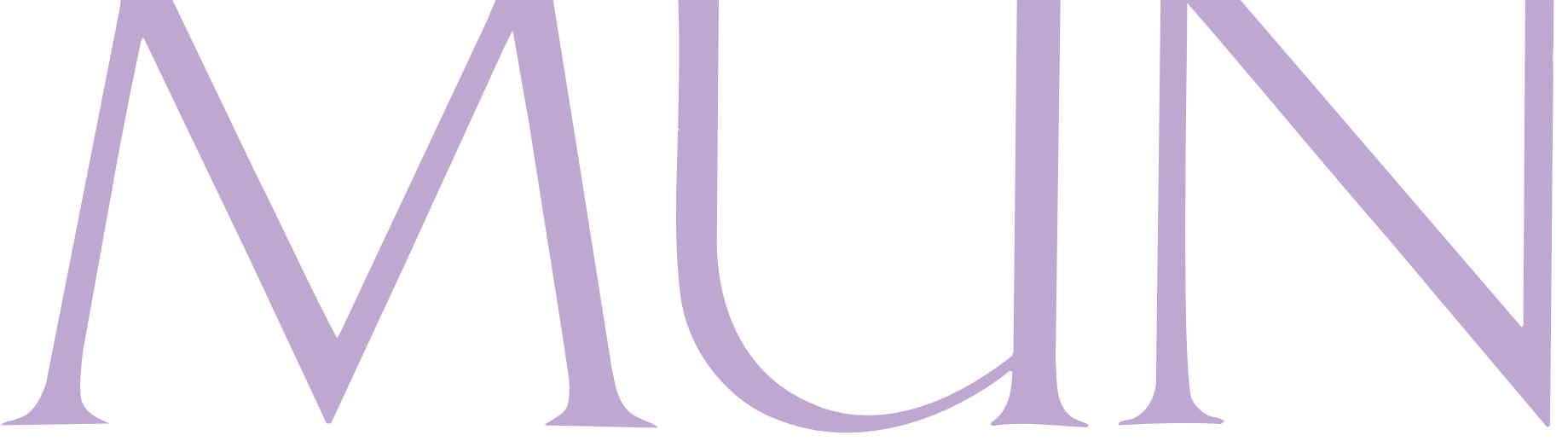

\title{
Surfando nas ondas gravitacionais
}

Previstas pela Teoria da Relatividade Geral (TRG), de Einstein, as ondas gravitacionais começaram o ano de 2016 chacoalhando a física. No dia 11 de fevereiro, David Reitze, representante do Observatório de Ondas Gravitacionais por Interferômetro de Laser (LIGO), nos Estados Unidos, confirmou a detecção direta dessas ondas. A comprovação deve inaugurar uma área de pesquisa na física com uma perspectiva inteiramente nova: a astronomia de ondas gravitacionais.

A astronomia estuda objetos nos confins do universo a partir de informações que ficam registradas na luz emitida por eles. Tradicionalmente, esses estudos são feitos por meio de observaçôes do universo através de ondas eletromagnéticas (micro-ondas, rádio, luz visível e infravermelha, raios -X, radiação gama) e raios cósmicos (partículas carregadas e neutrinos). As ondas gravitacionais também carregam informação sobre sua origem e sobre a natureza da própria gravidade, dados que, antes da detecção, não poderiam ser obtidos de outra maneira. "Seu uso abre, portanto, um novo canal para o estudo do universo e oferece

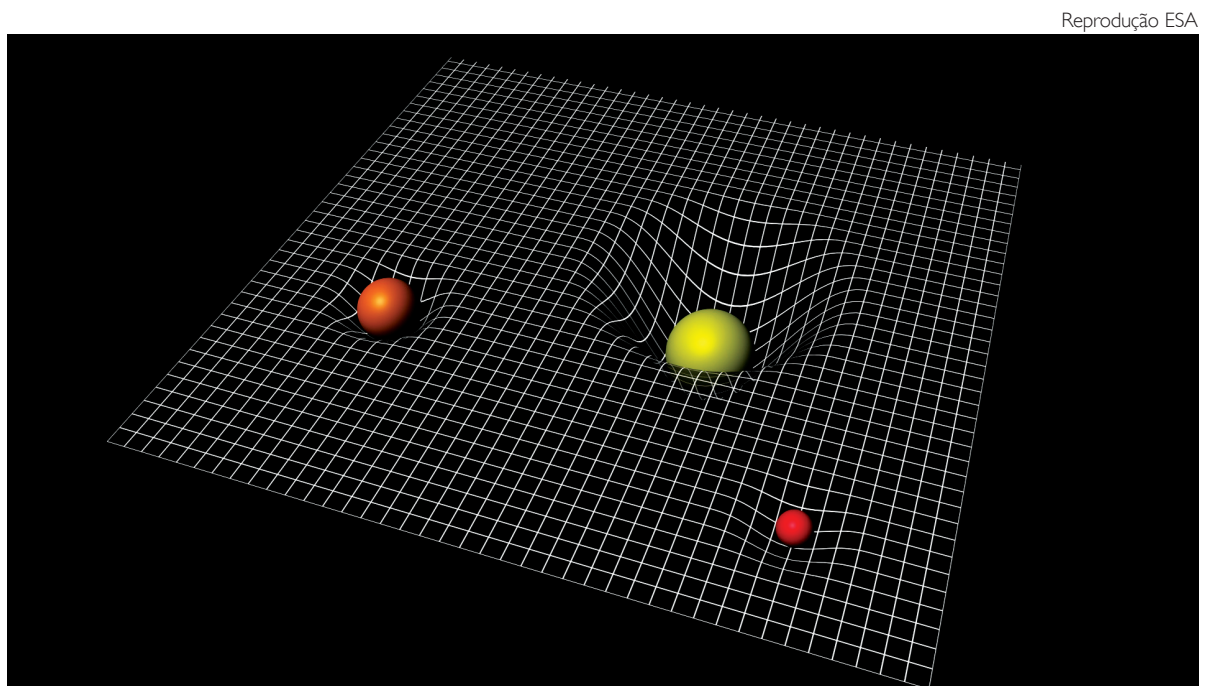

Concepção artística da distorção do tecido do espaço-tempo gerada por massas diferentes. Quanto maior a massa, maior a distorção que ela provoca no tecido do espaço-tempo e são essas distorções que conseguem manter os objetos em órbita, por exemplo

acesso a fenômenos que seriam difíceis de observar com os meios tradicionais", explica Carlos Escobar, do Fermi National Laboratory (Fermilab), nos Estados Unidos, e professor aposentado do Instituto de Física da Universidade Estadual de Campinas (Unicamp).

A versão final das equações da TRG que previam as ondas gravitacionais foi apresentada à Academia Prussiana de Ciências em 25 de novembro de 1915 . Segundo o historiador da ciência, David Kaiser, do Massachussetts Institute of Technology (MIT), nos últimos 100 anos a TRG se mostrou incrivelmente bem-sucedida. Aplicada por físicos e astrônomos em suas buscas no cosmo, nenhum experimento ou observação revelou qualquer discrepância na teoria. No entanto, a detecção das ondas gravitacionais permanecia como um dos grandes desafios da física contemporânea. Então, no dia 14 de setembro de 2015 , quase que simultaneamente, os detectores gêmeos do LIGO, localizados em Hanford, no estado de Washington, e em Livigston, Louisiana, revelaram distorções no espaço causadas pelas colisões de buracos negros. Para Escobar, isso representa outro teste bem-sucedido da TRG em um domínio no qual ela, até agora, não havia sido testada: o de campos gravitacionais muito intensos, caso da colisão de buracos negros. 


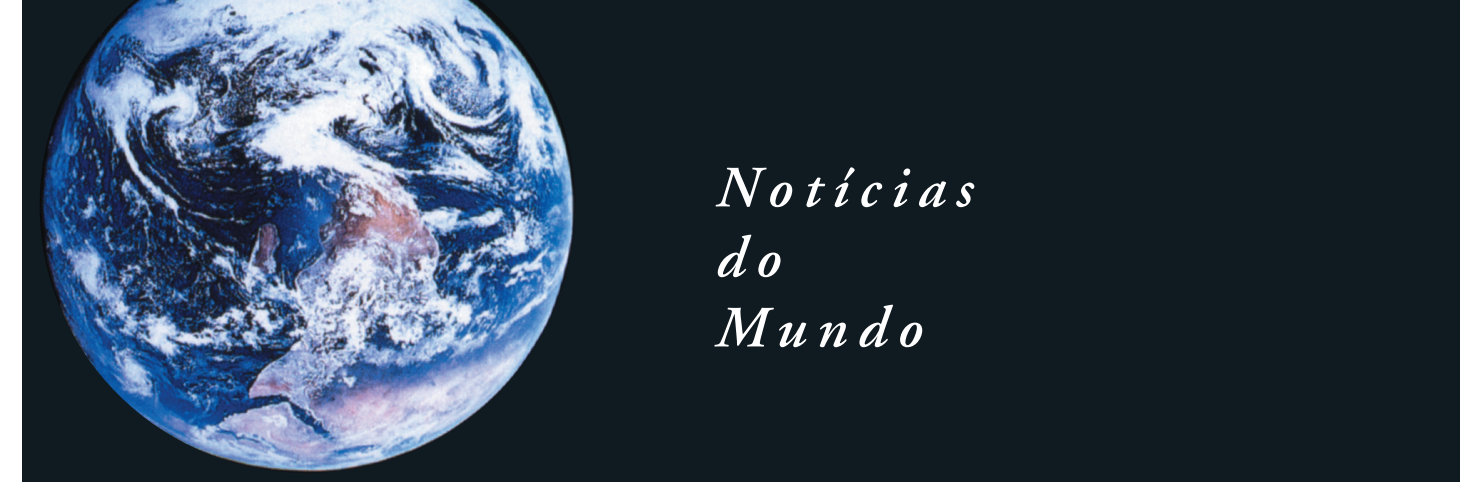

ALÉM DE NEWTON Isaac Newton (1643-1727) extraiu uma relação matemática entre as entidades físicas tempo, espaço e massa que explica a queda de uma maçã e a órbita da Lua em relação à Terra. Para Newton, a mesma força é responsável por ambos os movimentos: a gravidade. Einstein questionou a teoria newtoniana em seus alicerces e desenvolveu uma hipótese onde espaço e tempo estão intrinsecamente conectados. Para ele, o espaço-tempo é como um tecido cuja topologia se distorce pela presença de massa. A gravidade é uma distorção na geometria do espaço-tempo e não uma força. Para Escobar, "a TRG de Einstein vai além da teoria newtoniana porque abandona a ideia de ação instantânea a distância”.

As ondas gravitacionais, como todos os tipos de onda, são perturbaçôes. No caso das ondas gravitacionais, no entanto, a perturbação se forma no tecido espaço-tempo. Essas ondulações podem ser produzidas por eventos violentos, como a colisão de buracos negros e estrelas de nêutrons. As ondulações se propagam no espaço, chegando a "chacoalhar as coisas" perto do planeta Terra também, mas em uma escala muito pequena. Escobar explica que elas só podem ser detectadas em experimentos supersensíveis, como com os interferômetros do LIGO.
“[...] dentre todos os fenômenos, o mais excitante, o mais misterioso, o mais violento e mais extremo é o que tem o nome mais simples, comum, tranquilo e sereno. Trata-se tão somente de um 'buraco negro'”. Assim o escritor Isaac Asimov descreveu os buracos negros em seu livro $O$ colapso do universo (1977). Um buraco negro é um objeto que provoca uma distorção tão grande no espaço-tempo que nem mesmo a luz consegue escapar de seu horizonte de eventos. Não podemos usar a luz (ondas eletromagnéticas) emitida por um buraco negro para estudá-lo, mas podemos usar as ondas gravitacionais! Em 1993, os astrofísicos norte-americanos Russell Alan Hulse e Joseph Hooton Taylor Jr. receberam o Nobel de Física por demonstrar, em 1974, que em sistemas binários (por exemplo, um pulsar orbitando uma estrela de nêutrons), a energia escapa no formato de ondas gravitacionais. Por isso o tamanho do pulsar diminuía lentamente. Um par de buracos negros em rotação, orbitando entre si e ao longo de bilhôes de anos, começa a perder energia na forma de ondas gravitacionais. Essa perda de energia faz com que os buracos negros se aproximem gradativamente, avançando de forma mais rápida um em direção ao outro, até colidirem com velocidade aproximadamente igual à metade da velocidade da luz. O resultado: forma-se um único bu- raco negro mais massivo (parte da massa total do par é convertida em energia seguindo a famosa fórmula de Einstein $\mathrm{E}=\mathrm{mc}^{2}$ ).

Segundo um relatório da divisão de astrofísica do Instituto Nacional de Pesquisas Espaciais, Inpe, divulgado logo após o anúncio do achado das ondas gravitacionais, a análise do sinal detectado pelos interferômetros do LIGO permite concluir que as ondas se referem aos últimos 0,2 segundos de órbita de dois buracos negros em colisão (com massas respectivamente iguais a 29 e 36 vezes a massa do Sol). O buraco negro formado a partir da colisão teria uma massa igual a 62 vezes a massa solar. Os dados indicam maior probabilidade de que o evento de colisão tenha ocorrido em uma regiāo do céu no hemisfério sul, a uma distância aproximada de 1,3 bilhão de anos-luz da Terra (um ano-luz é a distância que a luz percorre em um ano, com a velocidade de $300 \mathrm{mil} \mathrm{km} / \mathrm{s}$ ).

BIG SCIENCE Idealizado nos anos 1980 por um grupo de físicos do Instituto deTecnologiadaCalifórnia(Caltech) e do MIT, o LIGO é um projeto financiado pela Fundação Nacional de Ciências (NSF). De acordo com o pesquisador do Inpe, Odylio Aguiar, o projeto custa à NSF entre U\$ 600 milhões e um U\$ 1 bilhão. É parte de uma colaboração científica internacional denominada LIGO Scientific 
